\title{
Factors related to primary health care provision: a cross-sectional study in an elderly rural population
}

\author{
Ana Maseda, José Carlos Millán-Calenti, Julia Carpente, José Luis Rodríguez-Villamil, \\ Camen de Labra
}

\begin{abstract}
We examined the relationship between social support, lifestyle habits, and disease-related factors in two primary health care settings: the health care center and the elders' homes. Logistic regression analysis was performed to determine the effect of independent variables on the provision of health care services. Those who received home visits were significantly older, had lower family income, and had poorer social support systems. Furthermore, elderly people with nutritional risk status, heart failure, functional dependence, or cognitive impairment were among those most likely to request in-home care visits. Our study suggests that age, nutritional risk, and functional dependence are the most important factors to predict the use of home health care services compared with general practitioner visits.
\end{abstract}

Keywords: elderly, health care services, risk factors

According to the World Health Organization (2002), the proportion of people over 60 years of age is growing faster than any other age group, and their problems, particularly those related to health care assistance, are receiving special attention. Older people not only need more personal care assistance as they age, but also advanced age has proved to be a strong predictor of the use of health services (Bowling, Farquhar, \& Browne, 1991; Newbold, Eyles, \& Birch, 1995).

The two health services most studied to date are hospital care services and formal home care assistance (Fernández-Mayoralas, Rodríguez, \& Rojo, 2000), the main reason being their substantial and continuously growing cost. But Spain's health care system has an important specific feature; it offers universal coverage as a constitutionally guaranteed right. Today the services offered by the Spanish National Health System to citizens include primary care and specialist care. Primary care covers most activities regarding health promotion, health education, disease prevention, health care, health maintenance and recovery, rehabilitation, and social work. Health care is delivered either at primary health care centers or in patients' homes, depending on the general practitioner's (GP) decision. In the case of serious mobility problems, severely impaired (cognitively or physically) people, frail and disabled older adults, terminally ill, and other persons for whom it would be impractical to visit the health care center, the patient or caregiver could ask the medical doctor in their local health care center for a home visit.

Therefore, the outpatient benefit portfolio includes primary care physicians' (PCP) visits and home care physicians' (HCP) visits, with elderly accounting for $40 \%$ of GP activity. Although the Spanish primary health care system has these two main places of health care provision, few studies have explored these types of assistance.

HCP visits are an important way of delivering primary health care services, but paradoxically, although older people use the health services the most (Bowling et al., 1991; Newbold et al., 1995), they are often excluded from these studies. Furthermore, most of the recent research exploring health services in elders comes from data collected in longitudinal studies (León-Muñoz et al., 2007), with the handicap of the mortality rate due to the advanced age of the sample or the duration of the study. Lastly, much of the research in this field is performed using secondary data obtained from medical records or from national community-telephone surveys, and rarely from data obtained personally by the physician (Taylor \& Hoenig, 2006). In this regard, cross-sectional studies including elderly people, whose data have been collected directly by a physician, would be necessary to identify the reliable risk factors that determine the use of primary health care resources. This information would be needed for appropriate public health policy and resource planning.

A relationship has been observed between sociodemographic variables, such as age (Bowling et al., 1991; Newbold et al., 1995), gender (Newbold et al., 1995; Redondo-Sendino, Guallar-Castillón, 
Banegas, \& Rodríguez-Artalejo, 2006), family incomes, and level of education (Kleinman, Gold, \& Makuc, 1981) and the use of different health services. However, since health status is a multidimensional concept other variables should be taken into account when trying to account for use of health care services, such as social support, lifestyle habits, and disease-related factors. While most of these variables have been evaluated independently, rarely have all been considered together, which has hampered the development of heuristic models for predicting various strategies preferred for health care service utilization within an established health care center or in the patient's home.

The impetus for this study is based on the fact that the available data on the Spanish primary health care service and its utilization are not complete, and there are insufficient studies on factors that influence the care setting, i.e., a health center or in the patient's home. The main purpose of this study is to explore, within a cross-sectional study, the shared relationship between sociodemographic, social support, lifestyle habits, and disease-related variables with the health care setting required by Spanish elderly in primary care. As previously stated, the Spanish health care system is free for all citizens so that economic variables do not apply in this case.

\section{Method}

\section{Participants}

This study was carried out in the Aranga Primary Health Care Center (Galicia, Spain). Our sample included 127 people aged 65 years and over requesting health care services, either in the health care center or at home. A systematic sampling method was employed to select a random sample, in which the first of every eight people requesting assistance was included. Patients were eligible to participate in the study if they met the following inclusion criteria: age $\geq 65$ years, request to the medical doctor for a programmed home visit, first diagnosis in the primary care center, and referral to specialist care. Patients were excluded from the study for the following reasons: refusal to sign the informed consent form, people $\geq 65$ who requested assistance for continued medicine prescription, and home visit demands to confirm deaths.

\section{Material and Procedure}

All participants were individually assessed by the same GP, either at the health center or at home. Before data collection, all patients gave written informed consent. The study protocol was approved by the Ethics Committee at the University of A Coruña and conformed to the principles embodied in the Declaration of Helsinki.

Age, gender, education, and marital status were included among the sociodemographic data. The Spanish version (Grau, Eiroa, \& Cayuela, 1996) of the standardized Older Americans Resources and Services (OARS) Social Resources Scale (Fillenbaum, 1998) was used to rate the adequacy of social support. It consists of seven items, which can be combined (Millán-Calenti, Sánchez, Lorenzo, \& Maseda, 2012) in three psychometrically identified subscales: the extent of contact with others, the satisfaction with contacts, and the availability of help when needed.

Tobacco and alcohol consumption was recorded. The variable smoking status was analyzed using a classification of non-smokers, ex-smokers, and current smokers according to the number of cigarettes smoked and based on a 30-day prevalence of cigarette smoking (i.e., whether or not someone had smoked a cigarette at any time during the past 30 days) (Lantz, 2003). According to the level of alcohol intake, the Spanish Health Care Information Institute (Instituto de Información Sanitaria, Ministerio de Sanidad, Política Social e Igualdad, 2011) defined "drinkers" as persons currently drinking an average of 30 grams or more of alcohol a day, compared with those drinking less than that amount or none ("non-drinker") or those with drinking history in the past ("ex-drinker").

Finally, disease-related variables such as illness, functional status, and psychological variables were collected. We got information about heart failure, osteoporosis, dementia, tumors, chronic obstructive pulmonary disease (COPD), diabetes, ulcers, hypertension, allergies, and vaccines. The nutritional risk status was assessed by the Nutrition Screening Initiative (NSI) checklist (Sahyoun, Jacqucs, Dallal, \& Russell, 1997) that includes 10 items determining a total nutrition risk score (range: $0-21$ ): $0-2=$ low; 3$5=$ moderate; $\geq 6$ = high nutritional risk. To assess basic activities of daily living (ADL), a Spanish adaptation (Baztán et al., 1993) of the Barthel index (Mahoney \& Barthel, 1965) was used. Patients' degree of dependence was classified into five groups: < 20 total; 20-35 severe; 40-55 moderate; 60-95 mild dependence; and 100 points (90 if they use wheelchair) independence. Other variables included were if the participants had been bedridden and had fallen. The fall definition was: "In the past month, have 
you had any falls including a slip or a trip in which you lost your balance and landed on the floor or ground or lower level?" (Lamb, Jorstad-Stein, Hauder, \& Becker, 2005). Participants were also assessed for the presence or absence of frailty (Ministerio de Sanidad y Consumo, 1996), considering frailty in older persons if they have three or more of the following criteria, or prefrailty if 1 or 2 components: Age over 75 years; relevant pluripathology; main pathology constituting a disabling disorder; presence of a prevailing or accompanying mental pathology; and any social problems concerning their health.

Associated with psychological variables, cognitive status was assessed using the Spanish version of the Mini-Mental State Examination (MMSE; Folstein, Folstein, \& McHugh, 1975), the Lobo's MiniExamen Cognoscitivo (MEC; Lobo, Ezquerra, Gómez Burgada, Sala, \& Seva Díaz, 1979), with a cut-off score of 23 (less than or equal to 23) indicating cognitive impairment. Lastly, the validated Spanish version (Fernández-San Martín et al., 2002) of the geriatric depression scale (GDS; Brink et al., 1982) was used to estimate the severity of subjects' depressive symptoms. This questionnaire was scored to yield a continuous scale from 0 to 30, with a score of 10 or higher indicating probable clinical depression.

\section{Data Analyses}

The software package IBM SPSS Statistics v.21.0 was used to perform all statistical analyses. Categorical variables were reported in terms of frequency and percentage. The $\chi 2$-test was used to test differences between groups (people receiving health care services in a primary care facility [PCP] or during home visits $[\mathrm{HCP}]$ ). In order to determine which variables modified a dichotomic dependent variable (PCP vs $\mathrm{HCP}$ ), a forward conditional logistic regression model was performed, with all the analyzed variables introduced in the model as predictors, from which the odds ratios (ORs) along with their 95\% confidence intervals (CIs) were calculated. Variables were entered into the regression procedure into four blocks: sociodemographic variables, social variables, lifestyle habits and disease-related variables. Categorical variables with more than two values were converted to dummy variables for inclusion in the multivariate models. ORs were calculated for each variable included in the model. A $p$-value less than .05 was considered statistically significant.

\section{Results}

The mean age of the 127 subjects selected was $77.6 \pm 8.4$ years; women accounted for the $60.6 \%$ of the sample. Regarding the distribution of the participants based on the place of health care provision, 71 $(55.9 \%)$ used general practitioner consultation, and $56(44.1 \%)$ were visited at home by the physician.

Table 1 shows the sociodemographic, social support, lifestyle habits, disease-related characteristics, and functional and psychological variables of the subjects who requested PCP or HCP visits. Among the sociodemographic variables, only age showed a significant association with the type of care requested, such that older persons were more likely to request HCP than PCP (92.9\% of the population aged 85 years and over was more likely to use home health service), whereas young people were more likely to request $\mathrm{PCP}$ compared to $\mathrm{HCP}(89.6 \%$ of those aged between $65-74$ years were more likely to use primary care physicians visits). The use of HCP visits was not found to be related to gender, level of education, or marital status.

With respect to social support, the three social subscales were associated with the type of health care provision. Elders with fewer connections with friends and relatives showed a higher percentage of requests for HCP visits than for PCP visits, with the contrary effect on those having adequate or extensive friendships $\left(\chi^{2}=20.65, p<.001\right)$. In terms of satisfaction with contacts, those less satisfied with the quality of their relationships showed a greater likelihood of requesting HCP visits than PCP visits, with the contrary effect on those with fairly or very satisfactory fellowships $\left(\chi^{2}=6.33, p=.042\right)$. Availability of help was also associated with the type of physician visits, with those having long term caregiver support requesting fewer home visits than did those with less availability of help $\left(\chi^{2}=8.77, p=.033\right)$.

No association among lifestyle habits, tobacco or alcohol consumption, and the type of visit required was found. Among disease-related factors, heart failure and nutritional risk were the only variables significantly associated with the use of health care services. Sixty-three percent of elders with heart problems and those considered to be at moderate $(51.6 \%)$ or high $(69 \%)$ nutritional risk were more likely to request HCP visits than moving to the health center.

Regarding functional dependence, the percentage of elders requesting HCP visits was significantly higher among those showing dependence in ADL (71.4\%) than among those evaluated as independent (22.5\%). Bedridden state, falls, and frailty were also associated with the type of care visits. Those patients being bedridden, reporting falls in the past month, or presenting frailty showed a significantly tendency to request home visits $\left(\chi^{2}=10.83, p=.001 ; \chi^{2}=6.33, p=.012\right.$; and $\chi^{2}=23.34, p<.001$, respectively). 
Table 1. Sociodemographic, social support, lifestyle habits, and disease-related factors of patients grouped according to whether they received health care services in a primary care facility (PCP) or during home visits (HCP)

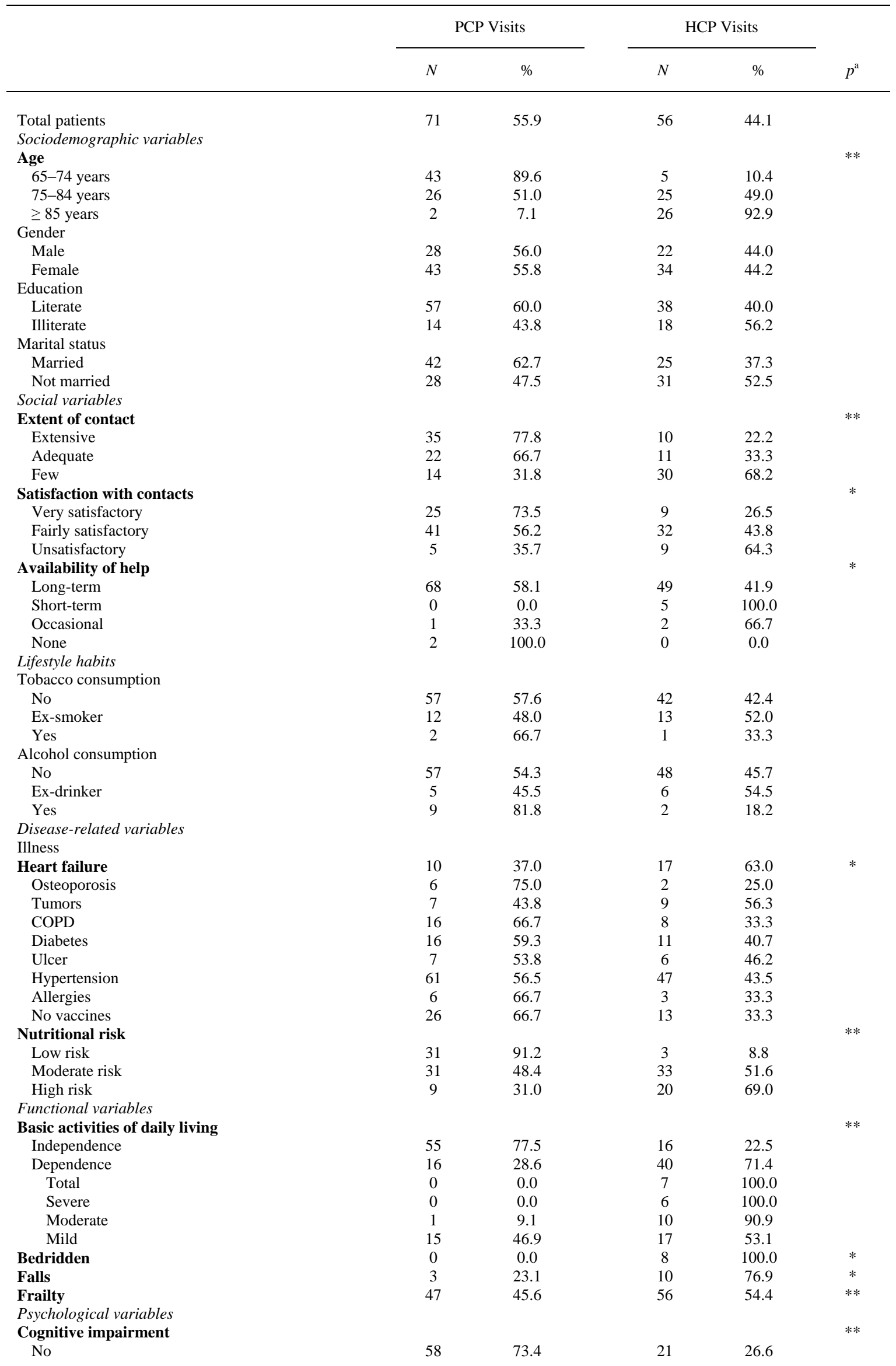




\begin{tabular}{|c|c|c|c|c|}
\hline Yes & 13 & 27.1 & 35 & 72.9 \\
\hline \multicolumn{5}{|c|}{ Depressive symptoms } \\
\hline No & 34 & 55.7 & 27 & 44.3 \\
\hline Yes & 37 & 56.1 & 29 & 43.9 \\
\hline
\end{tabular}

Notes: COPD = Chronic Obstructive Pulmonary Disease.

${ }^{\mathrm{a}}$ Chi-squared test. Significant values are indicated in bold: $* \mathrm{p}<.05 ;{ }^{* *} \mathrm{p}<.001$.

$N=$ number of elder people

Finally, cognitive impairment was significantly associated to the type of health care requested $\left(\chi^{2}=26.00, p<.001\right)$, while no association was found with depressive symptoms. We observed a higher and significant percentage of older people requesting home care visits when suffering from cognitive impairment.

All the variables included in the bivariate analysis were included as covariables in a multiple logistic regression analysis to assess the determinants of HCP visits (Table 2). Three out of all variables listed in Table 1 and considered for the analysis turned out to be important predictors of HCP visits. Age was the single best predictor of risk of HCP. Elderly people with advanced age were 7.008 times (95\% CI, 1.80627.194) more likely to report HCP visits than those younger. Other factors increasing the risk of reporting $\mathrm{HCP}$ visits were the risk of having nutritional problems (OR, 31.670; 95\% CI, 2.766-362.630) and the dependence in ADL (OR, 28.391; 95\% CI, 2.081-387.302). The combination of having all the factors increased the risk of having $\mathrm{HCP}$ visits to $83.3 \%$.

Table 2. Forward conditional logistic regression model with all the analyzed variables introduced as predictors and including only the three major predictor variables showing significant differences between primary and home care physicians' visits

\begin{tabular}{lccc}
\hline & B & $p$ & Odds Ratio (95\% CI) \\
\hline & & $* *$ & $7.008(1.806-27.194)$ \\
Age & 1.947 & $* *$ & $31.670(2.766-362.630)$ \\
Nutritional risk & 3.455 & $*$ & $28.391(2.081-387.302)$ \\
\hline
\end{tabular}

Notes. The complete model had a -2 likehood ratio of 76.662, Cox and Snell $R^{2} 0.535$, and Nagelkerke pseudo $R^{2} 0.716$. B = regression coefficient; $\mathrm{CI}=$ confidence interval.

${ }^{*} p<.05 ;{ }^{* *} \mathrm{P}<.001$.

Since age, dependence in ADL, and nutritional risk status were by far the best predictors of HCP visits, we analyzed each one of these variables separately. Table 1 shows the relationship between the range of age, the nutritional risk status (low, moderate, and high), the level of dependence in ADL and the place of health care provision demanded. Home visits increased as the range of patients' age increased, from $10.4 \%$ of people from 65 to 74 years demanding HCP to $92.9 \%$ in the group of elderly aged 85 years or over. In addition, these results showed a statistically significant difference $(p<.001)$ between the risk of having nutritional problems and HCP visits. The number of PCP visits decreased from $91.2 \%$ when there was low nutritional risk to $31.0 \%$ when the risk was high, while HCP visits increased from $8.8 \%$ when there was low nutritional risk to $69.0 \%$ when the risk was higher.

In relation to the categorization of subjects according to the ADL score and the place of health care demanded, we observed that while $77.5 \%$ of people requesting PCP visits were independent, $71.4 \%$ of those being attended at home were reporting some level of dependence $(41.1 \%$ of them from moderate level to total dependence) $\left(\chi^{2}=40.71, p<.001\right)$. The degree of dependence increased when PCP visits decreased (from $77.5 \%$ to $0 \%$ ) while the number of HCP visits increased at increasing the dependence level (from $22.5 \%$ to $100 \%$ ). 


\section{Discussion}

Numerous studies have found a relationship between health care utilization and factors related to the patient's sociodemographic variables, social support, lifestyle habits, disease-related characteristics, as well as functional and psychological variables (Bowling et al., 1991; Lamb et al., 2005; Ministerio de Sanidad y Consumo, INSALUD, 1996; Newbold et al., 1995). However, this is the first cross-sectional approach performed in a Spanish elderly rural population that examines the effects of all these variables taken together, within two health care settings (the health care center or the patient's home), and as such, it is an important contribution to identify the factors determining the demand for health services, and for home services in particular.

Literature on health service use has found that, regardless of country, older people are the major users of heath care services (Bowling et al., 1991; Newbold et al., 1995) that is also confirmed in the case of Spain (Fernández-Mayoralas et al., 2000). Our study goes a step further adding that Spanish elderly ( $\geq$ 80 years) are more likely to have more physician visits at home than at the health center. In our results, gender is not significantly associated with HCP. However, gender inequalities according to the type of health service used and the health problem for which care is required have been widely described in the literature. Women tend to be greater users of health services, but their use pattern depends in part on the type of service requested. This is due to the fact that women visit medical practitioners, receive home medical visits, and take a high number of medications (Redondo-Sendino et al., 2006) more frequently than men. The factors that best explain this greater utilization of health-care services could be the number of chronic diseases and their worse health-related quality of life.

The common opinion of GPs in the sense that most patients with heart-sink problems demand home visits is confirmed (Rutten, Heddema, Daggelders, \& Hoes, 2012). Heart failure is often accompanied by malnutrition, which in turn affects the course of the syndrome (Sargento et al., 2013). Our results highlight inattention to nutritional integrity as one of the most important predictors of HCP visits. As people age, their real income levels decline, and elderly individuals are forced to reallocate their limited resources. One of the most typical reallocations is to use funds budgeted for food and other items like housing and/or utilities. Since nutritional risk is the best predictor of a costly primary health service, coupled with costly comorbidities (Coombs, Barrocas, \& White, 2004) and psychological and social problems (Brownie, 2006), it would be prudent, not only from a GP viewpoint but also from a policy perspective, to emphasize the maintenance of the nutritional integrity among elderly. To initiate specific interventions such as modifying lifestyle of the elderly, creating workshops on good nutritional habits or introducing them in home-delivery meals programs are examples of initiatives that could be developed in order to sustain acceptable health status of the elderly.

Dependence on ADL was also a significant predictor of HCP visits. Greater utilization of home service by older adults with worse functional status confirms the results of previous cross-sectional (Wolinsky \& Johnson, 1991) and longitudinal studies (Krasnik, Hansen, Keiding, \& Sawitz, 1997). Our study also points out a negative relationship between level of dependence on ADL and PCP visits and a positive relationship with HCP visits. In other words, people with high dependence are more likely to request home visits whereas patients who rate themselves as highly independent are more likely to request going to see the PCP. This result could be explained because as we age, the number of chronic diseases increases (among them, cognitive impairment), making cognitive decline a predictor of functional dependence (Millán-Calenti, Tubío, et al., 2012). A negative correlation was observed between age and the MMSE score (Millán-Calenti et al., 2009) and this high cognitive decline implies a high loss of ability at carrying out ADL (Millán-Calenti, Tubío, et al., 2012). A greater number of limitations on instrumental activities of daily living and utilization of home services was also found in the Spanish older population (León-Muñoz et al., 2007).

Our study has several limitations as well as a number of strengths. Due to its cross-sectional nature, our first and major limitation is our inability to discuss our findings in terms of causal relationships in either direction between health service use and all the variables described. Second, we cannot rule out the possibility that other variables not included (other sociodemographic factors or some relevant determinants of primary health care variables, for example, self-reported health status), might explain in part the differences found in the use of health services. Finally, even though we studied the main types of health services in primary care demanded by the elderly (delivered at primary health care center or in the patient's home) it would also be interesting to evaluate other activities carried out in primary care, such as telephone consultation, diagnosis or radiological tests, or dental health (León-Muñoz et al., 2007). Despite these limitations, our study has several strengths. Firstly, to our best knowledge this is the first study which has evaluated the relationship between sociodemographic variables, social support, lifestyle habits, disease-related characteristics, functional and psychological variables and the place of health care provision among a rural population of elderly in Spain. Secondly, and in contrast with other countries, Spain has a national health insurance scheme which enables everyone to have access not only to primary 
care at no cost, covering all GP and specialist services, but also to hospitalizations. In this sense, the possible influences in the health care consumption caused by socioeconomic differences are excluded from the study. Besides, our data were collected by the physician himself and self-reported by the patient, which adds support to the reliability of our data. Lastly, the present research has clinical implications. Access to the different health care services is determined by the physician diagnosis. Therefore, an important role of GPs should be to pay more attention to chronic conditions such as nutritional risk or functional dependence, and guide the elder to an adequate health care service, saving time, money, morbidity, and quality of life. The assessment of these variables should therefore be integrated as an important part in the assessment of elderly patients to promote and offer care services adapted to the population's needs. Home-based care and consequently HCP visits, particularly in elderly people with special needs, should be promoted by primary care physicians as useful tools thus avoiding hospitalization or admission to long-term care institutions.

In conclusion, we observed a strong correlation between age, nutritional risk and functional dependence, and HCP visits. While home visits have long been a central element of general practice, they are now primarily reserved for elderly or palliative care patients, mainly because GP often complain of heavy workload and say such visits are an inefficient use of time, are often inconvenient, and are underfunded (Pereles, 2000). The possibility to provide HCP visits to elderly patients depends on the costs of medical care and the provision of these health services, which must be factored in considering the enormous pressure and need for improving efficient health care supported by the public sector. However, home services have many advantages such as providing the opportunity to gain additional information about patient's living conditions, family dynamics, caregivers burden, need for institutionalization, and, economically speaking, reduces other costs, mainly nursing home and hospital care. Besides, not only primary health services provided multiple benefits dealing with the mental health of older adults (Rybarczyk et al., 2013) but also home services (Yang, Garis, Jackson, \& McClure, 2009). This study provides enough data to raise health policies awareness on the need for giving appropriate financial incentives to guarantee the continuation of this traditional and cost-effective health care service in our population.

\section{Acknowledgments}

The authors sincerely thank the participants in the study for helping to increase the knowledge of primary health care. The authors declare that they have no competing interests.

\section{Notes}

Notes: COPD = Chronic Obstructive Pulmonary Disease.

${ }^{a}$ Chi-squared test. Significant values are indicated in bold: $* p<.05 ; * * p<.001$.

$N=$ number of elder people.

Notes. The complete model had a -2 likehood ratio of 76.662, Cox and Snell $R^{2} 0.535$, and Nagelkerke pseudo $R^{2} 0.716 . \mathrm{B}=$ regression coefficient; $\mathrm{CI}=$ confidence interval.

$* p<.05 ; * * p<.001$.

\section{References}

1. Baztán, J. J., Pérez del Molino, J., Alarcón, T., San Cristóbal, E., Izquierdo, G., \& Manzarbeitia, J. (1993). Índice de Barthel: Instrumento válido para la valoración funcional de pacientes con enfermedad cerebrovascular [Barthel Index: A valid instrument for functional assessment of patients with cerebrovascular disease]. Revista Española De Geriatría Y Gerontología, 28, 32-40.

2. Bowling, A., Farquhar, M., \& Browne, P. (1991). Use of services in old age: Data from three surveys of elderly people. Social Science \& Medicine, 33, 689-700. doi:10.1016/0277-9536(91)90023-6

3. Brink, T., Yesavage, J. A., Lum, O., Heersema, P. H., Adey, M., \& Rose, T. L. (1982). Screening tests for geriatric depression. Clinical Gerontologist, 1, 37-43. doi:10.1300/J018v01n01_06

4. Brownie, S. (2006). Why are elderly individuals at risk of nutritional deficiency? International Journal of Nursing Practice, 12, 110-118. doi:10.1111/ijn.2006.12.issue-2

5. Coombs, J. B., Barrocas, A., \& White, J. V. (2004). Nutrition care of older adults with chronic disease: Attitudes and practices of physicians and patients. Southern Medical Journal, 97, 560-565. doi:10.1097/00007611200406000-00010

6. Fernández-Mayoralas, G., Rodríguez, V., \& Rojo, F. (2000). Health services accessibility among Spanish elderly. Social Science \& Medicine, 50, 17-26. doi:10.1016/S0277-9536(99)00247-6

7. Fernández-San Martín, M. I., Andrade, C., Molina, J., Muñoz, P. E., Carretero, B., Rodríguez, M., \& Silva, A. (2002). Validation of the Spanish version of the geriatric depression scale (GDS) in primary care. International Journal of Geriatric Psychiatry, 17, 279-287. doi:10.1002/gps.588 
8. Fillenbaum, G. (1998). Multidimensional functional assessment of older adults. The duke older Americans resources and services procedures. Hillsdale, NJ: Lawrence Erlbaum Associates.

9. Folstein, M. F., Folstein, S. E., \& McHugh, P. R. (1975). "Mini-mental state". A practical method for grading the cognitive state of patients for the clinician. Journal of Psychiatric Research, 12, 189-198. doi:10.1016/00223956(75)90026-6

10. Grau, G., Eiroa, P., \& Cayuela, A. (1996). Versión española del OARS multidimensional Functional Assessment Questionnaire: Adaptación transcultural y medida de la validez. [Spanish version of the OARS Multidimensional Functional Assessment Questionnaire: Cross-cultural adaptation and validity measurement]. Atención Primaria, $17,486-495$.

11. Instituto de Información Sanitaria, Ministerio de Sanidad, Política Social e Igualdad [Healthcare Information Institute, Ministry of Health, Social Policy and Equality]. (2011). Codificación Clínica con la CIE-9-MC. Actualización en la codificación de enfermedades mentales [International Classification of Diseases, 9th rev, Clinical Modification]. Madrid, Spain: Ministerio de Sanidad, Política Social e Igualdad.

12. Kleinman, J. C., Gold, M., \& Makuc, D. (1981). Use of ambulatory medical care by the poor: Another look at equity. Medical Care, 19, 1011-1029. doi:10.1097/00005650-198110000-00004

13. Krasnik, A., Hansen, E., Keiding, N., \& Sawitz, A. (1997). Determinants of general practice utilization in Denmark. Danish Medical Bulletin, 44, 542-546.

14. Lamb, S. E., Jorstad-Stein, E. C., Hauder, K., \& Becker, C. (2005). Development of a common outcome data set for fall injury prevention trials: The prevention of falls network Europe consensus. Journal of the American Geriatrics Society, 53, 1618-1622. doi:10.1111/j.1532-5415.2005.53455.x

15. Lantz, P. M. (2003). Smoking on the rise among young adults: Implications for research and policy. Tobacco Control, 12 (Suppl 1), i60-i70. doi:10.1136/tc.12.suppl_1.i60

16. León-Muñoz, L. M., López-García, E., Graciani, A., Guallar-Castillón, P., Banegas, J. R., \& Rodríguez-Artalejo, F. (2007). Functional status and use of health care services: Longitudinal study on the older adult population in Spain. Maturitas, 58, 377-386. doi:10.1016/j.maturitas.2007.09.008

17. Lobo, A., Ezquerra, J., Gómez Burgada, F., Sala, J. M., \& Seva Díaz, A. (1979). El Mini Examen Cognoscitivo: Un test sencillo, práctico, para detectar alteraciones intelectivas en pacientes médicos [The Mini Examen Cognoscitivo: A simple and practical test to detect intellectual dysfunctions in psychiatric patients]. Actas Luso Españolas De Neurología Y Psiquiatría, 3, 189-202.

18. Mahoney, F. I., \& Barthel, D. W. (1965). Functional evaluation: The Barthel index. Maryland State Medical Journal, 14, 61-65.

19. Millán-Calenti, J. C., Sánchez, A., Lorenzo, T., \& Maseda, A. (2012). Depressive symptoms and other factors associated with poor self-rated health in the elderly: Gender differences. Geriatrics \& Gerontology International, 12, 198-206. doi:10.1111/j.1447-0594.2011.00745.x

20. Millán-Calenti, J. C., Tubío, J., Pita-Fernández, S., González-Abraldes, I., Lorenzo, T., \& Maseda, A. (2009). Prevalence of cognitive impairment: Effects of level of education, age, sex and associated factors. Dementia and Geriatric Cognitive Disorders, 28, 455-460. doi:10.1159/000257086

21. Millán-Calenti, J. C., Tubío, J., Pita-Fernández, S., Rochette, S., Lorenzo, T., \& Maseda, A. (2012). Cognitive impairment as predictor of functional dependence in an elderly sample. Archives of Gerontology and Geriatrics, 54, 197-201. doi:10.1016/j.archger.2011.02.010

22. Ministerio de Sanidad y Consumo, INSALUD. (1996). Criterios de ordenación de servicios para la atención sanitaria a las personas mayores [Services' organization criteria for sanitary care in the elderly]. Madrid, Spain: INSALUD.

23. Newbold, K. B., Eyles, J., \& Birch, S. (1995). Equity in health care: Methodological contributions to the analysis of hospital utilization within Canada. Social Science \& Medicine, 40, 1181-1192. doi:10.1016/02779536(94)00229-M

24. Pereles, L. (2000). Home visits. An access to care issue for the 21st century. Canadian Family Physician, 46, 2044-2048.

25. Redondo-Sendino, A., Guallar-Castillón, P., Banegas, J. R., \& Rodríguez-Artalejo, F. (2006). Gender differences in the utilization of health-care services among the older adult population of Spain. Public Health, 6, 155.

26. Rutten, F. H., Heddema, W. S., Daggelders, G. J. A., \& Hoes, A. W. (2012). Primary care patients with heart failure in the last year of their life. Family Practice, 29, 36-42. doi:10.1093/fampra/cmr047

27. Rybarczyk, B., Garroway, A. M., Auerbach, S. M., Rodríguez, V. M., Lord, B., \& Sadock, E. (2013). Primary care psychology: An opportunity for closing the gap in mental health services for older adults. Clinical Gerontologist, 36, 195-215. doi:10.1080/07317115.2013.767870

28. Sahyoun, N. R., Jacqucs, P. F., Dallal, G. E., \& Russell, R. M. (1997). Nutrition Screening Initiative checklist may be a better awareness/educational tool than a screening one. Journal of the Academy of Nutrition and Dietetics, 97, 760-764.

29. Sargento, L., Satendra, M., Almeida, I., Sousa, C., Gomes, S., Salazar, F., \& Palma Dos Reis, R. (2013). Nutritional status of geriatric outpatients with systolic heart failure and its prognostic value regarding death or hospitalization, biomarkers and quality of life. The Journal of Nutrition, Health \& Aging, 17(4), 300-304. doi:10.1007/s12603-013-0030-y

30. Taylor, D. H., \& Hoenig, H. (2006). Access to health care services for the disabled elderly. Health Services Research, 41(3p1), 743-758. doi:10.1111/hesr.2006.41.issue-3p1

31. Wolinsky, F. D., \& Johnson, R. J. (1991). The use of health services by older adults. Journal of Gerontology, 46, S345-S357. doi:10.1093/geronj/46.6.S345 
32. World Health Organization. (2002). Active ageing: A policy framework. Geneva, Switzerland: Author. Retrieved from: http://whqlibdoc.who.int/hq/2002/who_nmh_nph_02.8.pdf.

33. Yang, J. A., Garis, J., Jackson, C., \& McClure, R. (2009). Providing psychotherapy to older adults in home: Benefits, challenges, and decision-making guidelines. Clinical Gerontologist, 32, 333-346. doi:10.1080/07317110902896356 